\title{
MODERN DATABASE ON HUMAN AND MATERIALAND TECHNICAL RESOURCES IN EMERGENCY MANAGEMENT SYSTEMS
}

\author{
Miloš Milenkovićp ${ }^{*}$, \\ Dalibor Kekić2 \\ Darko Glavaš ${ }^{3}$, \\ Dušan Marković ${ }^{4}$ \\ Vladimir Nikolićs \\ ${ }^{1}$ Ministry of interior - Sector for emergency \\ managemen, \\ Belgrade, Serbia \\ ${ }^{2}$ University of Criminal Investigation and \\ Police Studies, \\ Belgrade, Serbia \\ ${ }^{3}$ The City of Belgrade - Secretariat \\ for Defense, Emergency Situations, \\ Communications and Coordination of \\ Public Relations, \\ Belgrade, Serbia \\ ${ }^{4}$ Singidunum University, \\ Belgrade, Serbia \\ ${ }^{5}$ Ministry of interior - Sector for emergency \\ managemen, \\ Belgrade, Serbia
}

\section{Keywords:}

database, human and material-technical resources, emergency situations and management.

\section{INTRODUCTION}

Databases are widely used in various fields. In addition, different definitions of the term database can be found in theory. A database is simply a collection of organized information, usually as a set of related lists of similar entries. The data is often organized in order to be easily accessible. Large databases are used all around the world in the police (criminal records - Department of motor vehicles - driving history, driving records), banks (all customers and their transactions) and in the Government (statistics, election information, tax records) [1]. From the previous definition, it is important to point out the part that indicates that large databases are being used in systems such as police, government or banks. There is a link to the use of databases in the field of emergency

\begin{abstract}
:
Emergencies caused by natural or man-made disasters have been occurring more in the last decade. The consequences of earthquakes, floods, fires are more catastrophic than before. People, material and cultural goods are suffering. Efficiency and effectiveness are the primary goals when it comes to responding to emergencies. In order to provide an adequate response as soon as possible, it is necessary that the responsible institutions have the necessary information on human and material-technical resources that can be available in the endangered territory. However, in this part usually, problems arise. Specifically, a lack of information on available resources has proven to be a barrier to providing the required level of response. However, the use of modern software solutions and databases can greatly help to eliminate these barriers. Time restrictions may be a key factor when responding to emergencies. Often, decision-makers are constrained in this regard and must make a response plan for a limited period of time. The ability to use a modern database on human and material-technical resources in emergency management systems provides a large number of possibilities in order to better respond to emergencies.
\end{abstract}

\author{
Correspondence: \\ Miloš Milenković \\ e-mail: \\ milos10jul@gmail.com
}


management with an emphasis on reviews of real and operationally usable human and material - technical resources. A database is an organized collection of information, usually with one central topic. In a computer database (as opposed to a paper database), the program that you use to enter and manipulate the data is either a database program or a database management system (DBMS) [2]. In this definition, the emphasis is placed on the fact that the database in most cases is focused on a single central parameter. In the case of an emergency management system, this would be an opportunity to review the available human and material resources at any time and depending on the need. Furthermore, the development of databases in this area may have different ways of access. Databases can be developed depending on the scope of the data to be covered, then the level of decision for which purposes will be used and depending on the territorial distribution that the database will cover. When it comes to the amount of data that will be used in emergency management databases, database creators need to clearly prioritize the specific group of data that will constitute the contents of the database. Obviously, such databases should not have too much, and at the same time, too little data. This means that the database must not be overloaded with information that will not be used in any emergency caused by natural or man-made disasters. So, database creators need to find the optimum when it comes to the data that will make up the database. Another criterion that must be considered is the level of decision maker who will use the database. This part is more about the software implementation and implies that research should be conducted on who and what profile of persons will later use the database when making decisions about resource allocation in different emergencies. The database must be tailored to these persons. This means looking at their IT skills and creating a database that would be simple and easy to use. When it comes to territorial coverage, it is possible to create databases for macro or micro-location. For example, many countries around the world take this topic seriously. India is a good example of a developed database in this area. Towards supporting country's efforts the efficient management of natural disasters, The Indian Space Research Organization has evolved a comprehensive space-based Disaster Management Support (DMS) programmed and institutionalized the same in association with concerned ministries/agencies. To support the total cycle of disaster/emergency management for the country, in near real-time, the database creation is addressed through National Database for Emergency Management (NDEM), a GIS based repository of data.
NDEM is envisaged to have core data, hazard-specific data, and dynamic data in the spatial form as well as textual form. The database enables the development of a decision support system in the form of customized user interfaces with necessary security mechanisms [3]. The National Database for Emergency Management (NDEM) Version 3.0 Released is currently being developed. The portal is browser independent and compatible to all computer devices and mobile phones with vector rendering services. One and very important part of the salient features of the NDEM Version 3.0 is a resource management module for the allocation and monitoring of relief resources [4]. The emphasis in one part of this database is precisely on the allocation and monitoring of emergency resources. In this part, it should be pointed out that such databases can also be used in the case of humanitarian aid provided to countries affected by emergencies. Namely, in addition to human and material resources that are primarily focused on an operational response in the case of natural and man-made disasters, humanitarian aid consists of goods such as food, sanitary, cosmetic, medical and similar equipment, which are also needed by the vulnerable population in the case of an emergency. Other countries are also developing their own databases on human and material resources that may be operational immediately before, during, and after an emergency situation. Good examples are United States, Russian Federation, and others.

\section{THE ROLE OF DATABASES ON HUMAN AND MATERIAL - TECHNICAL RESOURCES IN THE EMERGENCY MANAGEMENT}

Emergency management involves several phases. Disaster Risk Management includes few activities, programes, and measures which can be taken up before, during and after a disaster with the purpose to avoid a disaster, reduce its impact or recover from its losses. The three key stages of activities that are taken up within disaster risk management are as follows:

- Before a disaster (pre-disaster) - disaster mitigation and disaster preparedness,

- During a disaster (disaster occurrence) - emergency response,

- After a disaster (post-disaster) - recovery [5]

Considering the importance of databases in an emergency management system, it is obvious that each of the above mentioned phases has the need for quality data- 
bases containing information on human and material resources that should be available at all times. If we start from the preparation and prevention phase, then the database must contain descriptions of all the subjects participating in the prevention section. What would this practically mean? For example, if floods are taken as a referent natural disaster, the database should provide review into all the requested data pertaining to entities working on the preventive action of flood protection and defense. These would be data on the human and material resources of the water management companies, which build embankments, coastal fortifications and channel network systems. It is also important for decision-makers to understand what action is being taken at all times to prevent floods in order to know whether the eventual flood risk is reduced, reduced to a level of acceptability or eliminated altogether. Before moving on to the next phase of emergency management, human and material resource databases also play a very significant role in the immediate danger phase. This should cover a period of several hours before the danger itself. It is crucial for decision-makers, for example the management of the competent emergency management headquarters or the competent emergency management institutions, to have information on what resources they have for disposal for a particular threat that should threaten people, material and cultural property. The next phase is maybe the most important part of emergency management. It is the response phase, where we can find the most important role of databases on human and material - technical resources. Namely, the absence of such databases put decision makers, operational management or commanders of rescue units in a very uncomfortable position. In situations where even minutes decide on someone's life or property, it is clear that decision-makers must have a complete picture to respond to a natural or man-made disaster. If the database contains everything that decision makers need about human and material resources, they will have a much easier job. The question is what are the key data that one database in this field should contain. We will take an example of a national database. Data, which will be part of the national database, should be:

- number of personnel,

- a specialty of people,

- affiliation with a particular organization and institution,

- the location of the organization/institution involved in the event of a specific emergency (list of all facilities and branches),
- available machinery - quantity and type,

- means of transport available - quantity and type,

- rescue equipment available - quantity and type,

- review of medical facilities with capacity,

- review of accommodation and food preparation facilities.

This data framework is only the basic level of data that these databases must contain. Of course, depending on the risk, the necessary information can be added. For the sake of complete transparency and availability of data, the database can also be combined with advanced software solutions through which data is presented on mapping content. One suggestion is to use the GIS - geographical information system. Through this application, a link to the database can be made on the maps to provide decision makers a more meaningful and accessible overview of available human and material resources. Finally, databases are also needed for the last phase of the emergency management cycle. It is a recovery phase. During this phase, decision makers need to look through the database to find out what resources they have in order to complete the rehabilitation phase and return life conditions to normal.

It is also important to point out that the content of databases on human and material and technical resources depends on several parameters, such as end users and the extent of the territory to which the database relates. Only up-to-date data have to be part of the database. Without up-to-date data, meaning and importance are lost, as is the inability to make the right decisions.

\section{SOFTWARE SOLUTIONS FOR DATABASES ON HUMAN AND MATERIAL - TECHNICAL RESOURCES IN THE EMERGENCY MANAGEMENT}

We will use the example of the possible software solution for a database on human and material - technical resources in the Sector for emergency management as an organizational unit of Ministry of interior of the Republic of Serbia.

Considering that these resources are distributed on the whole territory of the Republic of Serbia, where the majority of these resources are state-owned as the equipment of the Ministry of the interior, the most optimal solution is to have a database for managing human and material - technical resources as the user application of information system of the Ministry of the interior. 
IT system of the Ministry of interior has an adequate IT infrastructure for this task. Data entry into the database would be performed by the persons responsible for updating the situation in each of the 27 territorial organizational units of the Sector for emergency management. Upon entry, the data should immediately become available to decision makers both locally and at the headquarters of the Sector for emergency management. The presentation of the data contained in the reports should be flexible and adjusted to the current situation and the requirements of the management.

It should also be defined access control for the database and different permissions for data entry, then the production of specific reports as well as for user administration, modification of data nomenclature, or for customization of the data set to be entered into the database. The software should be used primarily by employees of the Sector for emergency management of the Ministry of interior, and, if necessary, through certain services, it should be allowed limited access to other institutions of importance that need the above information. Data insight should be vertical, meaning that decision makers at the national level should have complete access to all data, while at the regional level it should be restricted to the regional unit and the neighboring regional units.

It is important to note that it is necessary to replicate the database to another, physically remote location, which in the event of failure and termination of the primary site will assume its role and allow the smooth operation of the service.

If we take into account the existing software solutions for database development it is obvious that there are several options. One of the simplest is to use excel files that would be used with multiple addresses. With this solution, and if we have a local area connection, all users in the network can have access to any file. Not only that, but any changes made to the file can also be tracked. We can also set which users would have access to the file [6]. In this way, local users can create a database with the number and specifications of various resources that can be activated in the event of emergencies of local character. In addition, through shared excel files, decision makers at the highest level can have access to the same database and thus make optimal decisions on how to help local authorities. The disadvantage of this software solution is the fact that it is very slow in case you have to make the quick search as well as to generate reports. The next option is to use MS Access. Microsoft Access is a Database Management System (DBMS) from Microsoft that combines the relational Microsoft Jet Database Engine with a graphical user interface and software-development tools. It is a part of the Microsoft Office suite of applications, included in the professional and higher editions. It stores data in its own format based on the Access Jet Database Engine. Like relational databases, Microsoft Access also allows you to link related information easily. For example, customer and order data. It can also import or link directly to data stored in other applications and databases. MS Access can also understand and use a wide variety of other data formats, including many other database file structures [7]. These are some of the features that can be useful when creating a database on human and material and technical resources in emergency management by MS Access.

One good example is a software solution for creating a database of health facilities and resources that can be activated in case of natural or man-made disasters. It is called the LiveProcess Emergency Manager. It is a proven system for emergency preparedness planning, mass mobilization, real-time coordination and tracking healthcare emergency management platforms for every type of healthcare organization and agency. Hospitals and health systems, ambulatory centers, home health agencies, nursing homes, and public agencies use LiveProcess Emergency Manager to prepare for and respond to disaster events and for everyday coordination [8].

As an example of good practice, we can use the project "Disaster Reduction, Standardized Hazard Analysis and Risk Evaluation (DR SHARE"), which was created as a result of the cooperation of several institutions from Serbia, Croatia and Bosnia and Herzegovina. The main aim of this project is to improve risk management with the reducing the consequences, intensity and frequency of natural and man-made disasters, as well as protecting the population, the environment and property through the exchange of good practices, harmonizing methodologies in the three countries and creating new IT solutions that can help manage risks in the border region between Croatia, Serbia and Bosnia and Herzegovina [9].

The next example is connected with the project "Supporting the Management of Natural Disasters Risk - Comprehensive Early Warning System". The project "Supporting the Management of Natural Disasters Risk - Comprehensive Early Warning System" is implemented by the Public Investment Management Office, as a new body of the Government of the Republic of Serbia, with the support of the World Bank and with donations from Switzerland. One of the results of this project is a new digital platform - The Disaster Risk Information System (DRIS). The Disaster Risk 
Information System (DRIS) is an integrated emergency management system that contains all the digitized relevant information that exists in the disaster risk assessments and protection and rescue plans of all emergency management levels in the Republic of Serbia. Data can be accessed from the DRIS platform from many different levels so that the local self-government units will be able to see the current state of affairs, which through this platform also updates the data, but also the state administration bodies, especially the Sector for emergency management. Through the use of accurate and up-to-date information, the efficient exchange of information, and the faster involvement of entities at different levels, the information system will enable a more effective response to risks and disasters. Until now, at the Serbian-Korean Information Access Center (SKIP Center) as a part of the Ministry of Public Administration and Local Self-Government, trainings were organized for representatives of local government units to use the new application (DRIS) [10], . It is expected that this application will greatly contribute to a more efficient and effective response in emergencies. It is important to note that disaster risk assessments identify risks, their level and degree of acceptability. Measures to be taken to mitigate risk are also suggested in the risk assessment. Later, the plans for protection and rescue specify the activities to be carried out in accordance with the identified risks. Plans also provide information on human and logistical resources that should be used in real emergencies. This confirms that the Disaster Risk Information System (DRIS) is a good example of the database on human and material - technical resources in emergency management.

International cooperation is also a significant factor in emergency management. Natural disasters, such as floods, often affect multiple states simultaneously. In addition, in some situations, states can not respond independently to an emergency, so they need assistance from other countries. Assistance can be provided in the form of rescue forces and operations teams or through humanitarian assistance, equipment and relief supplies. One example is the database that is used by European civil protection and humanitarian aid operations as a part of the European Commission. The European Emergency Disaster Response Information System (EDRIS) is a database that lists annual contributions made by the Member States' Ministries of Foreign Affairs and the European Commission's Civil Protection and Humanitarian Aid Operations (ECHO) for the delivery of humanitarian assistance to people affected by natural or man-made disasters worldwide. It also provides information on how much each EU Member State contributes to a disaster response operation and to which area. EDRIS contains records of humanitarian aid contributions dating back to 1999 and it is free of access for reporting purposes. However, recording national humanitarian aid contributions and data input is restricted to the Member States' Ministries of Foreign Affairs. Member States are responsible for encoding the information. Information on EU funding is transferred from EDRIS to the global humanitarian Financial Tracking System managed by the UN. EDRIS also feeds in data into the EU Aid Explorer - an EU-wide database on humanitarian and development aid funding [11].

\section{THE POTENTIAL USE OF NEW SOFTWARE SOLUTION}

In the previous parts, the basic characteristics that the new software solution should satisfy are presented. It is necessary to indicate how the practical realization of the software solution should look and what advantages the use should bring.

Firstly, a software solution that should be used is a database created in a way that allows the useful and functional queries to be asked by end-users. It is very important that the database at the start is adequately created and adapted to the end-users, in this case to the decision-makers of different levels in emergency management. This means that the masks that make up the database provide a clear overview of the data needed to make a decision during some emergency situations. For example, if a flood occurs, the decision-maker needs to see through the database the schedule of the nearest teams with boats that can participate in the evacuation of the endangered population. Or, if an earthquake has occurred, decision-makers need to inspect the nearest entities to the endangered area that have machinery that can be used to excavate the rubble. In most cases someone who makes a decision before or during an emergency situation is limited in time. Therefore, it is necessary that the software that would be developed for these needs, or the database, be simple for end users and at the same time to provide the ability to easily and quickly search for data in order to make an efficient and effective decision. Secondly, attention must also be paid to what data is entered into the database. The validity and accuracy of the data is very important. Incorrect data can lead decision makers in the wrong direction. 
In the area of emergency management, one wrong decision can cause a series of negative consequences that are reflected in human casualties or material damage. This is just one of the reasons why it is necessary to enter only accurate and current data when creating a database. Moreover, it is important to have trained people who will enter data relevant to this type of database. Further, the importance of developing such software and database is reflected in several facts. It often happens that decision makers do not have enough information and data in situations when minutes decide on someone's life in situations of threat from floods, fires, earthquakes and more. However, if they have a modern database with the ability to make quick queries and obtain accurate data on human and material - technical resources, they will greatly facilitate the decision - making process. In addition, software that should enable compatibility with GIS layers should also provide the ability to make optimal decisions. One of the benefits that is provided is the connection with other databases that contain data of importance for emergency management. Examples are cadastral databases, then demographic and infrastructure databases. Linking databases on the human and material and technical resources with the aforementioned databases, allows users more opportunities to direct them towards the efficient and effective solutions. In this way, the possibility of mapping and displaying data on maps of different formats is obtained. This is another option that complements software or a database intended for decision makers in emergency management. Current practice shows sporadic examples of such databases used in the world. However, countries that do not have adequate databases on human and material and technical resources have visible problems in allocating the forces of the system of protection and rescue. By developing the database they should get a useful tool that can be used in various emergency situations and thus to contribute to the reduction of human casualties and consequences for property and material and cultural goods. In terms of the financial aspect, it is obvious that significant financial resources would not be allocated for the development and further use of such databases. One of the disadvantages is that the database on human and material resources must be constantly updated. It must not happen that inaccurate or outdated data is in the database. This can cause later problems when making a decision during an emergency.

\section{CONCLUSION}

Practice shows that after every natural and manmade disaster, an adequate analysis is required. The analyzes conducted have shown as one of the main conclusions that a lot depends on timely decisions and optimal allocation of resources. Most decision makers seek accurate data and information to make optimal decisions.

Database on human and material - technical resources can be a very useful tool in emergency management. Properly set parameters, updated data, and search and reporting criteria make databases very useful for emergency responders. Without databases, it is difficult to expect that optimal resource allocation will be made. A complete inventory of the information needed during the emergency response is often lacking, as well as a good structure for storing the information. The data structuring would facilitate fast access to a desired piece of information, as well as the automation of analysis of the information, and its use in the decision-making process. A database system provides for these: an organized way of storing the information, mechanisms that enable fast access, and functionality for the analysis of the information [12].

It is very important to have developed databases at all levels, both nationally and locally. In addition, it is of great importance that the database is up-to-date in order to provide decision makers in emergency management a platform for optimal allocation of human and material and technical resources.

\section{REFERENCES}

[1] C. A, "COMP 1001 - Introduction to Computers for the Arts and Social Sciences," School of Computer Science, Carleton University, 2004.

[2] D. E, "What is a Database," The Journal of World Intellectual Property 5(6), p. 981 - 1011 , 2005.

[3] I. S. R. O. Application, "isro.gov," 2013. [Online]. Available: https://www.isro.gov.in/national-database-emergency-management-ndem-servicestackling-disasters. [Accessed 0503 2020].

[4] D. o. s. -. I. S. R. O. N. v. 3.0., "isro.gov," 2015. [Online]. Available: www.isro.gov.in/nationaldatabase-emergency-management-ndem-version30-released. [Accessed 0503 2020].

[5] H. Khan, L. Vasilescu and A. Khan, "Disaster management cycle - a theoretical approach," Institute of Information Technology, Abbottabad, Pakistan; University of Craiova, Romania; University of Science and Technology, Bannu, Pakistan., 2008. 
[6] B. J.B., "How to share an excel file for easy collaboration.," 2019. [Online]. Available: https://helpdeskgeek.com/office-tips/how-to-share-an-excel-filefor-easy-collaboration. [Accessed 3003 2020].

[7] T. Point, "MS Access tutorilas point," 2018. [Online]. Available: https://tutorialspoint. [Accessed 30 03 2020].

[8] B. e. m. software, "LiveProcess Emergency Manager," 2020. [Online]. Available: https://www.g2.com/ products/liveprocess-emergency-manager/reviews. [Accessed 3003 2020].

[9] E. A. F. A. Vojvodina, "Project DR Share.," 2016. [Online]. Available: http://www.vojvodinahouse.eu/ src/kancelarija-u-briselu/aktivnosti/286/projekatdr-share-predstavljen-na-konferentsiji-u-briselu. [Accessed 1003 2020].
[10] T. D. R. I. S. (DRIS), " Project Supporting the Management of Natural Disasters Risk - Comprehensive Early Warning System.," 2020. [Online]. Available: http://skipcentar.rs/en_GB/vesti/nova-dris-aplikacija-omogucice-bolje-reagov. [Accessed 1903 2020].

[11] E. c. p. a.h. a. operations, "The European Emergency Disaster Response Information System (EDRIS)," 2020. [Online]. Available: https://ec.europa.eu/ echo/resources-campaigns/online-databases_en. [Accessed 2503 2020].

[12] S. Dilo and A. Zlatanova, "Data modelling for emergency response," Delft University of Tchnology, 2010. 